(c) American Dairy Science Association, 2006.

\title{
Indirect Chiral HPLC Determination and Fluorimetric Detection of D-Amino Acids in Milk and Oyster Samples
}

\author{
S. Rubio-Barroso, ${ }^{1}$ M. J. Santos-Delgado, C. Martín-Olivar, and L. M. Polo-Díez \\ Department of Analytical Chemistry, Faculty of Chemistry, Complutense University of Madrid, 28040 Madrid, Spain
}

\begin{abstract}
The indirect chiral method, based on the $o$-phthaldialdehyde reaction using the chiral N-acetyl-L-cysteine reagent, has been optimized to determine $\mathrm{D}$-amino acids in milk and oyster samples. Both the derivatization reaction and the HPLC separation have been improved, and simple sample treatments were proposed. The milk sample preparation involved centrifugation and filtration through polytetrafluoroethylene filters for determination of free D-AA. Two methods, nonenzymatic and enzymatic, were applied to determination of free and total D-AA, respectively, in oyster samples. The D-AA contents were in the range of 0.14 to $4.32 \mathrm{mg} / \mathrm{L}$ for milk samples and 0.80 to $15.9 \mathrm{mg} / \mathrm{g}$ for oyster samples, with relative standard deviations lower than $10 \%(\mathrm{n}=4)$, except for D-Tyr. In general, mean recoveries were greater than $90 \%$ with relative standard deviations lower than $9 \%(\mathrm{n}=4)$ at concentration levels from 0.055 to $0.426 \mathrm{mg} / \mathrm{L}$ for milk samples and 0.348 to $1.10 \mathrm{mg} /$ $\mathrm{g}$ for oyster samples.
\end{abstract}

Key words: D-amino acid, derivatization reaction, HPLC, fluorimetric detection

\section{INTRODUCTION}

The importance of amino acids in a variety of bioscience areas and food analysis is well established (Table 1). As is well known, AA can be present in food as free molecules or combined with proteins, and may be present as L- or D-isomers. The beneficial effects of LAA are well accepted; however, there are disagreements in the literature about the beneficial activities of D-AA; a nonexhaustive review regarding the activity of D-AA, which confirms these disagreements, is summarized in Table 1. Furthermore, transformations from L- to D-AA by effect of alkalinity, temperature, microorganisms, and processing have been described (Man and Bada, 1987; Williams, 1988; Cesapó et al., 1995; Hamase et al., 2002).

Received May 20, 2005.

Accepted July 7, 2005.

${ }^{1}$ Corresponding author: srubioba@quim.ucm.es
Available analytical techniques for L- and D- discrimination include gas chromatography (Casal et al., 2000; Erbe and Brückner, 2000; Brückner and Schieber, 2001; Lee et al., 2001) and capillary electrophoresis (Chang et al., 1998; Vandenabeele-Trambouze et al., 2000) although HPLC is the predominant method. Direct chiral methods use chiral stationary phases (Kato et al., 1998; Petritis et al., 2001). Indirect chiral methods are based on conventional reversed HPLC, either combined with a chiral mobile phase or with derivatization reactions using chiral additives (Buck and Krummen, 1987; Brückner et al., 1995; Erbe and Brückner, 2000). The resulting diastereoisomers are separated by reverse phase-HPLC (RP-HPLC). Currently, when easy and specific derivatization reactions are available, the use of indirect methods may be an advantageous alternative, assuming that the chiral additive is available in a pure form. The $o$-phthaldialdehyde (OPA) derivatization method has mostly been used; chiral reagents such as $\mathrm{N}$-isobutylryl-L- or D-cysteine, $\mathrm{N}$-acetyl-D-penicillamine, and N-acetyl-L-cysteine (NALC) have been proposed (Buck and Krummen, 1987; Brückner et al., 1995; Erbe and Brückner, 2000).

Regarding sample preparation, centrifugation of milk samples may be sufficient for determination of free AA in methanol medium (Jin et al., 1999). However, limited data are available for preparation of oyster samples, although similar mollusc samples have been hydrolyzed in acid medium for analysis of free AA (Felbeck and Wiley, 1987).

In this paper, due to the increasing demand for indepth knowledge about the role of D-AA in foods, several AA were determined in milk and oyster samples; $\mathrm{L}$ - and D-AA as free AA in milk and oyster samples, as well as total AA in oyster samples. Improvements, both in the OPA derivatization reaction and in the indirect HPLC method using the NALC chiral reagent, are proposed. Results of the presence of D-AA in these samples are presented.

\section{MATERIALS AND METHODS}

\section{Apparatus and Materials}

A chromatographic system equipped with the following components was used: a CM 4000 high-pressure 
Table 1. Beneficial and harmful activities of D-amino acids

\begin{tabular}{|c|c|c|c|c|}
\hline $\begin{array}{l}\text { Amino } \\
\text { acid }\end{array}$ & Beneficial activity & Reference & Harmful activity & Reference \\
\hline Serine & $\begin{array}{l}\text { Endogenous modulator of the } \\
\text { retina, and neuronal activity }\end{array}$ & $\begin{array}{l}\text { Wolosker et al. (2002) } \\
\text { Estevens et al. (2003) } \\
\text { Miller (2004) }\end{array}$ & $\begin{array}{l}\text { Inductor of nephrotoxicity } \\
\text { Pathophysiology of Alzheimer's } \\
\text { Damage to renal function }\end{array}$ & $\begin{array}{l}\text { Ganote et al. 1974) } \\
\text { Hamase et al. (2002) } \\
\text { Man et al. (1987) } \\
\text { Hamase et al. (2002) }\end{array}$ \\
\hline & $\begin{array}{l}\text { Therapeutic agent for the } \\
\text { treatment of schizophrenia }\end{array}$ & Hamase et al. (2002) & $\begin{array}{l}\text { Increase of production of free radicals } \\
\text { Associated with cow mastitis }\end{array}$ & $\begin{array}{l}\text { Gonzalez et al. (2003) } \\
\text { Cesapo et al. (1995) }\end{array}$ \\
\hline Threonine & & & $\begin{array}{l}\text { Affects the neurotransmitter balance } \\
\text { in the brain which may have } \\
\text { consequences during early postnatal life }\end{array}$ & Boehm et al. (1998) \\
\hline Alanine & $\begin{array}{l}\text { Novel cancer gene therapy } \\
\text { paradigm }\end{array}$ & Stegman et al. (1998) & $\begin{array}{l}\text { Pathophysiology of Alzheimer's disease } \\
\text { Damage to renal function } \\
\text { Increase of production of free radicals } \\
\text { Associated with cow mastitis }\end{array}$ & $\begin{array}{l}\text { Hamase et al. (2002) } \\
\text { Hamase et al. (2002) } \\
\text { Gonzalez et al. (2003) } \\
\text { Cesapo et al. (1995) }\end{array}$ \\
\hline Tyrosine & $\begin{array}{l}\text { Chiral precursor with } \\
\text { antiinflammatory activity }\end{array}$ & Hansford et al. (2003) & Increase of production of free radicals & Gonzalez et al. (2003) \\
\hline Valine & & & $\begin{array}{l}\text { Associated with cow mastitis } \\
\text { Autogenesis and maintenance of tumors }\end{array}$ & $\begin{array}{l}\text { Cesapo et al. (1995) } \\
\text { Man et al. (1987) }\end{array}$ \\
\hline
\end{tabular}

gradient pump (Milton Roy, Ribera Beach, FL), a Rheodyne model 7125 injection valve with a $20-\mu \mathrm{L}$ loop (Cotati, CA), a Perkin-Elmer LS 30 luminescence spectrometer (Norwalk, CT) and a Milton Roy CI 4100 integrator. A Chromasil C-18, 5- $\mu$ m particle size column $(150 \times 4.6$ mm i.d.; Análisis Vínicos, Ciudad Real, Spain) kept at constant termperature in a P-Selecta Presciterm bath (Barcelona, Spain) at $30^{\circ} \mathrm{C}$ was used for D- and L-AA separations and a Phenomenex safeguard column (Torrance, CA) was also used. A P-Selecta ultrasonic bath was used for shaking. A P-Selecta Meditronic centrifuge, able to apply $3,700 \times g$, and a Beckman J2-21 ultracentrifuge $(23,000 \times g)$ were used for the preparation of milk and oyster samples, respectively. Solvents for preparing the mobile phase were filtered through Phenomenex nylon membrane filters with $0.45-\mu \mathrm{m}$ pore size and the sample extracts were also filtered using polytetrafluoroethylene (PTFE) membrane filters, (13 $\mathrm{mm}, 0.5-\mu \mathrm{m}$ pore size; MFS, Dublin, CA) in the Visiprep vacuum manifold system (Supelco, Bellefonte, PA).

\section{Chemicals}

Amino acids used were: D- and L-Ser, D- and L-Thr, D- and L-Ala, D- and L-Tyr, D- and L-Val, D- and L-Trp, and D- and L-Leu (Sigma Chemical Co., St. Louis, MO, and Fluka, Buchs, Switzerland). Standard aqueous solutions of D- and L-AA at concentration levels of $25 \mathrm{mg} /$ $\mathrm{L}$ were prepared and stored in glass bottles at $4^{\circ} \mathrm{C}$. $o$-Phthaldialdehyde, NALC (Sigma and Fluka), and sodium borate (Scharlau, Barcelona, Spain) were used for the derivatization reaction. The protease enzyme pronase E from Streptomyces griseus (Sigma) with ac- tivity of $7.3 \mathrm{U} / \mathrm{mg}$ ( $75 \%$ enzyme, $25 \%$ calcium acetate) was used for the enzymatic hydrolysis of the oyster samples and the Bacillus subtilisin protease (Merck, Darmstadt, Germany) with activity of $9.7 \mathrm{U} / \mathrm{mg}$ was tested. Pure methanol (HPLC grade), tetrahydrofuran (THF), and sodium phosphate from Scharlau were used. The mobile phase was degassed with helium (Carburos Metálicos, Barcelona, Spain). Water was purified with a Milli-Q system (Millipore, Bedford, MA).

\section{Samples}

The sample types analyzed were cow's milk (whole, half-cream, and skimmed; Cremosita, Lugo, Spain); fresh oysters ( $85 \%$ water, $15 \%$ oyster) from the Ostranor vivarium (Cantabria, Spain) and lyophilized oysters from European Commission Environment Institute Laboratory Reference Materials, T36-Oyster Tissue, (Joint Research Center, Ispra, Italy).

\section{Derivatization Reaction}

The derivatizing reagent was prepared by mixing 3 $\mathrm{mg}$ of NALC (dissolved in $2.5 \mathrm{~mL}$ of $0.2 \mathrm{M}$ sodium borate buffer solution, $\mathrm{pH} 10.4$ ) with $0.5 \mathrm{~mL}$ of the OPA methanolic solution, $6 \mathrm{mg} / \mathrm{mL}$. Then, 10 to $200 \mu \mathrm{L}$ of the Dand L-AA mixture at $25 \mathrm{mg} / \mathrm{L}$ concentration level or a suitable volume of the sample were added to the above buffer solution, made up to $2 \mathrm{~mL}$, and mixed with 250 $\mu \mathrm{L}$ of the chiral NALC derivatizing reagent; the mixture was shaken for 2 min in an ultrasonic bath. 
Table 2. Optimized variables by HPLC method

\begin{tabular}{|c|c|c|c|c|}
\hline & Variable $^{1}$ & $\begin{array}{l}\text { Published } \\
\text { conditions }^{2}\end{array}$ & \multicolumn{2}{|c|}{ Proposed method conditions } \\
\hline Derivatization reaction & $\begin{array}{l}\text { OPA/NALC, mol ratio } \\
\text { OPA/AA, mol ratio } \\
\text { V Methanol, mL } \\
\text { Borate buffer, } \mathrm{M} \\
\text { pH } \\
\text { t reaction, min }\end{array}$ & $\begin{array}{l}1 / 1 \\
1 \\
0.4 \\
10.0 \\
10\end{array}$ & $\begin{array}{l}2 / 5-8 / 5 \\
50 / 1-300 / 1 \\
1-2 \\
0.1-0.4 \\
9.5-10.6 \\
1-30\end{array}$ & $\begin{array}{l}4 / 5 \\
100 / 1 \\
1 \\
0.2 \\
10.4 \\
2\end{array}$ \\
\hline
\end{tabular}

${ }^{1} \mathrm{OPA}=o$-Phthaldialdehyde; NALC $=\mathrm{N}$-acetyl-L-cysteine; $\mathrm{THF}=$ tetrahydrofuran; $\mathrm{t}_{\text {reaction }}=$ reaction time $(\mathrm{min}) ; \mathrm{q}=$ flow rate.

${ }^{2}$ Buck and Krummen, 1987.

${ }^{3}$ Knouder, Berlin, Germany.

${ }^{4}$ Chromasil, Analisis Vinicos, Ciudad Real, Spain.

\section{HPLC Determination}

The mobile phase was prepared by mixing $12.5 \mathrm{mM}$ sodium phosphate buffer solution, $\mathrm{pH} 6.5$ (solvent A) with methanol/solvent A/THF (vol/vol/vol: 100/60/6; solvent B). The gradient profile shown in Table 2 was applied with a flow rate of $1 \mathrm{~mL} / \mathrm{min}$ at $30^{\circ} \mathrm{C}$. Fluorimetric detection was carried out at 344 and $443 \mathrm{~nm}$ excitation and emission wavelengths, respectively. The injection volume of derivatized AA was $20 \mu \mathrm{L}$. The peak areas were used for quantification of AA and the retention times were used for identification purposes. To obtain the calibration graph, the derivatization reaction was applied to D- and L-AA solution mixtures at 5 concentration levels between 57 and $1240 \mu \mathrm{g} / \mathrm{L}$. The above HPLC method was applied to obtain the calibration of standard series for D- and L-AA quantification.

\section{Sample Preparation}

Milk Samples. For determination of free AA, $2.5 \mathrm{~mL}$ of milk was diluted with purified water in a $10-\mathrm{mL}$ glass flask. This solution was centrifuged at $3,700 \times g$ for 10 min and then filtered through a PTFE filter by means of the Visiprep vacuum system. The derivatization reaction was applied to $50 \mu \mathrm{L}$ of the prepared solution and the diastereoisomers were analyzed by HPLC. For recovery studies, D- and L-AA were added to the samples at 3 concentration levels in the range of 0.055 to 0.426 $\mathrm{mg} / \mathrm{L}$ for D-AA.

Oyster Samples. Two procedures were applied for determination of free and total D- and L-AA. For determination of free AA, $0.2 \mathrm{~g}$ of lyophilized sample or 1.3 $\mathrm{g}$ of fresh sample was weighed and transferred to a 30 -mL centrifuge tube, adding $5 \mathrm{~mL}$ of $0.1 \mathrm{M}$ sodium phosphate ( $\mathrm{pH}$ 7.5) buffer solution. The extraction was carried out by heating at $40^{\circ} \mathrm{C}$ for $15 \mathrm{~min}$, and the mixture was then shaken in an ultrasonic bath for 30 $\mathrm{min}$ and centrifuged at $23,000 \times g$ for $30 \mathrm{~min}$. The supernatant was transferred into a $10-\mathrm{mL}$ glass flask and the residue was washed with $3 \mathrm{~mL}$ of purified water, which was then transferred to the flask. Finally, water was added to $10 \mathrm{~mL}$, and the mixture was filtered through PTFE membrane filters. Aliquots of $25 \mu \mathrm{L}$ were used for the derivatization reaction.

For total AA determination, the samples were hydrolyzed enzymatically in 2 steps; $20 \mathrm{mg}$ of pronase $\mathrm{E}$ 
was added to $0.2 \mathrm{~g}$ (lyophilized oyster) or $1.3 \mathrm{~g}$ (fresh oyster) in a $30-\mathrm{mL}$ centrifuge tube; then, $5 \mathrm{~mL}$ of 0.1 $M$ sodium phosphate buffer ( $\mathrm{pH} 7.5$ ) solution was added. The mixture was sonicated in the ultrasonic bath for $30 \mathrm{~min}$ and subsequently heated to $37^{\circ} \mathrm{C}$ in the water bath for $24 \mathrm{~h}$. Then, another $20 \mathrm{mg}$ of the enzyme was added and heated to $37^{\circ} \mathrm{C}$ for $24 \mathrm{~h}$. The mixture was centrifuged at $23,000 \times g$ for $30 \mathrm{~min}$. The supernatant was transferred into a $10-\mathrm{mL}$ glass flask and the residue was washed as above with $3 \mathrm{~mL}$ of purified water. Then, water was added to $10 \mathrm{~mL}$, and the mixture filtered through a PTFE membrane filter. One milliliter of sample was diluted to $20 \mathrm{~mL}$ and 25 $\mu \mathrm{L}$ aliquots were used for the derivatization reaction. For recovery studies, D- and L- AA were added to the solid samples at 2 concentration levels of 0.348 and 1.10 $\mathrm{mg} /$ of oyster.

\section{RESULTS AND DISCUSSION}

\section{HPLC Method}

The chromatographic HPLC method was based on the derivatization reaction of $\mathrm{D}$ - and L-AA with OPA and NALC as chiral reagents. Based on the literature (Buck and Krummen, 1987), and in the absence of adequate detail, different variables involved in the derivatization reaction and in the chromatographic separation had to be optimized, including resolution. Optimum experimental conditions and available data from literature are summarized in Table 2. As can be seen, the proposed method reduces the derivatization reaction time by a factor of 5 and decreases the borate concentration by half. The reaction efficiency was around 94 and 99\% for L-Ser and D-Trp, respectively, with relative standard deviations in the range from 1 to $7 \%(n=4)$. Regarding the chromatographic separation, the increase in THF in the mobile phase allowed the resolution of $\mathrm{D}$-Val and L-Trp to baseline; on the other hand, the decrease of the phosphate buffer concentration by a factor of 4 is advantageous. In these optimum conditions, $7 \mathrm{AA}$ enantiomer pairs were resolved in $25 \mathrm{~min}$. The elution order was D- and L-Ser, D- and L-Thr, Dand L-Ala, L- and D-Tyr, L- and D-Val, L- and D-Trp, and D- and L-Leu. The change of elution order for some Dand L-AA pairs is in agreement with literature (Buck and Krummen, 1987; Jin et al., 1999).

Retention times were used to identify the D- and LAA and the standard calibration procedure was applied for their quantification. Figure 1a shows a representative chromatogram for standard solutions obtained in optimum conditions.

\section{Analytical Characteristics for Standards}

The D- and L-AA concentrations tested at 5 levels ranged from 57 to $1240 \mu \mathrm{g} / \mathrm{L}$. Table 3 shows the results obtained. Linearity was observed in all cases with regression coefficients around 0.999 . The relative standard deviations (RSD) at concentration levels of 260 to $680 \mu \mathrm{g} / \mathrm{L}$ in the middle of the linear ranges studied were from 1 to $6 \%(n=6)$ and detection limits, defined as 3 times the signal-to-noise ratio, were between 0.02 and $0.17 \mathrm{ng}$. The retention times with RSD values in the range 0.50 to $3.8 \%(\mathrm{n}=6)$ are also given in Table 3 . The D- and L-AA standard solutions were significantly stable for at least $10 \mathrm{~d}$ at $4^{\circ} \mathrm{C}$.

\section{Determination of $D-A A$}

Milk Samples. The sample preparation procedure was based on that proposed in the literature for the determination of nonprotein tryptophan in yogurts (Biasiolo et al., 1995). For the determination of free DAA, centrifugation and filtration steps were used. The optimized proposed procedure was applied to determine free D-AA in whole milk, half-cream, and skimmed milk samples. The results are shown in Table 4 . As can be seen, 5 D-AA were found in all samples; D-Tyr presented poor resolution, which justifies its high RSD. D-Threonine and D-Val were not detected. The D-AA (D-Ala, DVal, and D-Leu) have been found by other methods in milk samples (Casal et al., 2000) and D-Ala, D-Leu, DVal, and D-Ser have been found in cheese (Bruckner and Hausch, 1990) as well as in mastitis milk samples (Cesapó et al., 1995). The amounts of free D-AA were lower than $1 \mathrm{mg} / \mathrm{L}$ for D-Ser, D-Ala, and D-Tyr; the amounts of D-Trp and D-Leu ranged from 1.1 to $4.3 \mathrm{mg} /$ L. These results are in agreement with those found by other researchers for some D-AA (Cesapó et al., 1995; Casal et al., 2000). D-Amino acid content seems to depend on the type of process applied to milk; for example, the amounts of free D-AA, D-Ser, D-Ala, and D-Trp were lower in skimmed milk than in whole milk; the amounts of D-Tyr and D-Leu were highest in skimmed milk. According to the literature, the relatively large amounts of D-AA in milk samples could be due to heat treatment in the sterilization or pasteurization processes (Man and Bada, 1987; Williams, 1988; Cesapó et al., 1995). The RSD values were equal to or lower than $10 \%$ except for D-Tyr as indicated above. The relative high contents of D-Trp and D-Leu are obviously due to the low content of the respective L-AA. Figure $1 \mathrm{~b}$ shows the chromatogram for free D- and L-AA in a whole milk sample.

Oyster Samples. To determine D-AA in oyster samples, the 2 procedures specified earlier, nonenzymatic and enzymatic, were applied for the extraction and determination of free and total D-AA, respectively. The 

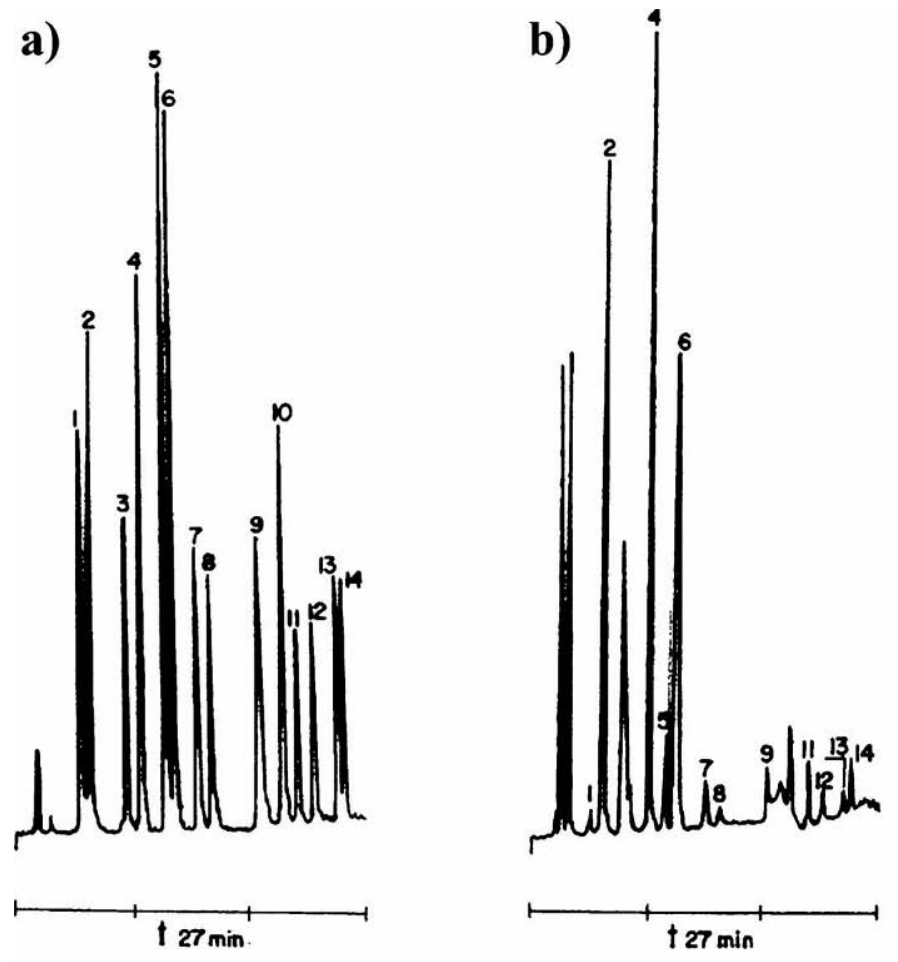

c)

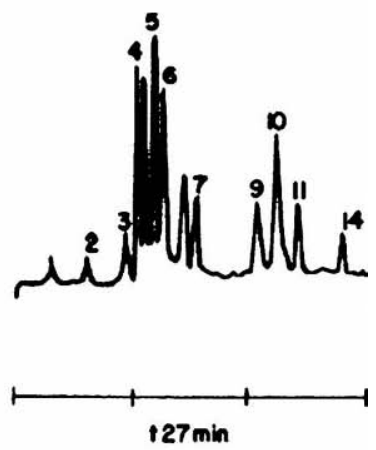

Retention time, min

Figure 1. Chromatograms of the standard and samples. a) Standard mixture of 7 D- and L-AA; b) Whole milk sample, and c) Lyophilized oyster sample analyzed by the enzymatic method. Peaks: $1=$ D-Ser; $2=\mathrm{L}-\mathrm{Ser} ; 3=\mathrm{D}$-Thr; $4=\mathrm{L}-\mathrm{Th}$; $5=\mathrm{D}-\mathrm{Ala} ; 6=\mathrm{L}-\mathrm{Ala} ; 7=\mathrm{L}-\mathrm{Tyr} ; 8=\mathrm{D}-$ Tyr; 9 = L-Val; 10 = D-Val; 11 = L-Trp; 12 = D-Trp; 13 = D-Leu; and 14 = L-Leu.

enzymatic hydrolysis method for the total determination of D-AA is based on that for the determination of seleno-amino acids in animal tissues, tuna, and mussels (Quijano et al., 2000), but the method had to be opti- mized for D-AA determination. For enzymatic hydrolysis of the samples, 2 nonspecific proteases were tested, subtilisin and pronase $\mathrm{E}$ at $\mathrm{pH} 7.5$ using 2 buffer solutions, Tris and sodium phosphate; pronase $\mathrm{E}$ in sodium

Table 3. Analytical characteristics for standards

\begin{tabular}{lllllll}
\hline $\begin{array}{l}\text { Peak } \\
\text { No. }\end{array}$ & $\begin{array}{l}\text { Amino } \\
\text { acid }\end{array}$ & $\begin{array}{l}\mathrm{RL},{ }^{1} \\
\mu \mathrm{g} / \mathrm{L}\end{array}$ & $\begin{array}{l}\mathrm{RSD},{ }^{2} \\
\%\end{array}$ & $\begin{array}{l}\mathrm{DL},{ }^{3} \\
\mathrm{ng}\end{array}$ & $\begin{array}{l}\mathrm{t}_{\mathrm{R}}, \\
\mathrm{min}^{4}\end{array}$ & $\begin{array}{l}\mathrm{RSD}, \\
\%\end{array}$ \\
\hline 1 & D-Ser & $57.0-465$ & 2 & 0.11 & 5.12 & 3.8 \\
2 & L-Ser & $57.0-465$ & 3 & 0.02 & 5.78 & 3.6 \\
3 & D-Thr & $124-620$ & 3 & 0.14 & 8.52 & 2.1 \\
4 & L-Thr & $124-620$ & 4 & 0.02 & 9.72 & 1.4 \\
5 & D-Ala & $57.0-465$ & 6 & 0.07 & 11.7 & 1.1 \\
6 & L-Ala & $57.0-465$ & 5 & 0.02 & 12.3 & 1.1 \\
7 & L-Tyr & $106-530$ & 2 & 0.10 & 14.0 & 1.0 \\
8 & D-Tyr & $106-530$ & 2 & 0.10 & 15.0 & 1.2 \\
9 & L-Val & $120-620$ & 4 & 0.17 & 18.0 & 1.4 \\
10 & D-Val & $120-620$ & 5 & 0.04 & 20.0 & 1.2 \\
11 & L-Trp & $124-1240$ & 1 & 0.17 & 21.5 & 0.85 \\
12 & D-Trp & $124-1240$ & 2 & 0.07 & 22.9 & 0.68 \\
13 & D-Leu & $115-575$ & 3 & 0.12 & 24.4 & 0.51 \\
14 & L-Leu & $115-575$ & 2 & 0.10 & 24.9 & 0.50 \\
\hline
\end{tabular}

${ }^{1} \mathrm{RL}=$ Range of linearity (studied range).

${ }^{2} \mathrm{RSD}=$ Relative standard deviation $(\mathrm{n}=6$, at concentration level of 260 to $680 \mu \mathrm{g} / \mathrm{L}$ ).

${ }^{3}$ Detection limit, DL $=3 \mathrm{~S} / \mathrm{N}$ (signal/noise).

${ }^{4} t_{R}=$ Reaction time. 
Table 4. Determination of amount of free D-amino acids in milk samples

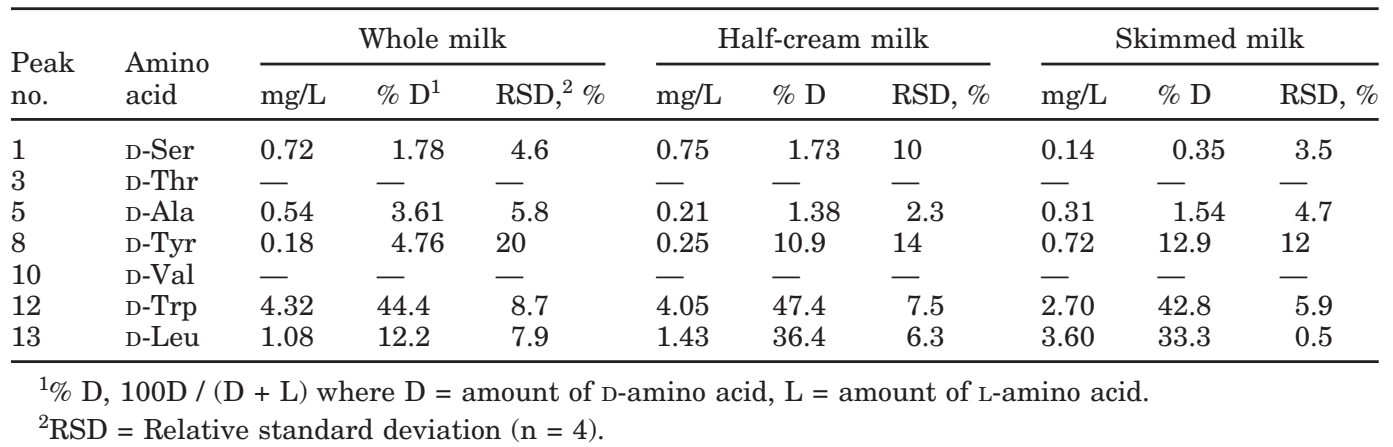

phosphate medium was selected because the area peaks were slightly higher indicating that this enzyme is more efficient than subtilisin. To achieve total enzymatic hydrolysis of the samples, the enzyme was added in 2 steps according to the procedure specified earlier.

The nonenzymatic method for free D-AA determination was the same as that for the enzymatic method except for addition of the enzyme. The developed method specified earlier was applied. It is based on a single extraction with a phosphate buffer at $\mathrm{pH}$ 7.5. Four extraction temperatures were tested because the peak areas were similar at 40,60 , and $80^{\circ} \mathrm{C}$ but slightly higher than at $22^{\circ} \mathrm{C}$; therefore, $40^{\circ} \mathrm{C}$ was selected for further work to minimize the risk of a racemization reaction. For both methods, it should be emphasized that it was not necessary to remove polar lipids with organic solvents.

Analysis of the extracts was carried out by applying the same derivatization reaction and the HPLC method optimized above. Figure 1c shows a chromatogram from a lyophilized oyster sample after applying the enzymatic method. The results obtained for determination of free and total D-AA in lyophilized and fresh oyster samples are shown in Table 5. Only 3 D-AA were found, D-Thr, D-Ala, and D-Val. The D-Ala and D-Val in the free form were found in both lyophilized and fresh oyster samples. Regarding total D-AA, D-Thr, D-Ala, and DVal were always found in lyophilized and fresh oyster samples. In all cases, the contents were lower in lyophilized oyster, which may be due to the effect of the lyophilization process. In any case, D-AA contents are relatively high; this may have something to do with their presence in microorganism cell walls (Bruckner and Hausch, 1990; Cesapó et al., 1995; Hamase et al., 2002).

\section{Recovery Studies from Milk and Oyster Samples}

Validation of the proposed procedures for D-AA determination was carried out by means of recovery studies. Matrix effect was not observed in any case. Milk samples were spiked with D- and L-AA mixtures at 3 concentration levels, and the experimental methods were applied. The results are showed in Figure 2. Mean recoveries were in the range 92 to $95 \%$. The RSD values were lower than $5 \%(\mathrm{n}=4)$ in all cases.

Regarding oyster samples, 2 D- and L-AA concentration levels were tested. The results obtained by applying the enzymatic procedure to lyophilized and fresh oyster samples are shown in Figure 3. In general, recoveries were higher than $90 \%$ and the RSD values were lower

Table 5. Determination of D-amino acids in oyster samples

\begin{tabular}{|c|c|c|c|c|c|c|c|c|c|c|c|c|c|}
\hline \multirow{3}{*}{$\begin{array}{l}\text { Peak } \\
\text { no. }\end{array}$} & \multirow{3}{*}{$\begin{array}{l}\text { Amino } \\
\text { acid }\end{array}$} & \multicolumn{6}{|c|}{ Lyophilized oyster } & \multicolumn{6}{|c|}{ Fresh oyster $^{1}$} \\
\hline & & \multicolumn{3}{|c|}{ Free AA } & \multicolumn{3}{|c|}{ Total AA } & \multicolumn{3}{|c|}{ Free AA } & \multicolumn{3}{|c|}{ Total AA } \\
\hline & & $\mathrm{mg} / \mathrm{g}$ & $\% \mathrm{D}^{2}$ & $\mathrm{RSD}^{3} \%$ & $\mathrm{mg} / \mathrm{g}$ & $\% \mathrm{D}$ & $\mathrm{RSD}, \%$ & $\mathrm{mg} / \mathrm{g}$ & $\% \mathrm{D}$ & $\mathrm{RSD}, \%$ & $\mathrm{mg} / \mathrm{g}$ & $\% \mathrm{D}$ & $\mathrm{RSD}, \%$ \\
\hline 1 & D-Ser & - & - & - & - & - & - & - & - & - & - & - & - \\
\hline 3 & D-Thr & - & - & - & 1.37 & 26.3 & 3 & - & - & - & 4.63 & 13.6 & 3.5 \\
\hline 5 & D-Ala & 1.12 & 31.3 & 1 & 5.26 & 43.7 & 1 & 3.36 & 39.2 & 4.6 & 15.9 & 40.2 & 2.9 \\
\hline 8 & D-Tyr & - & - & - & - & - & - & - & - & - & - & - & - \\
\hline 13 & D-Leu & - & - & - & - & - & - & - & - & - & - & - & - \\
\hline
\end{tabular}

${ }^{1}$ Concentrations refer to dry samples.

${ }^{2} \% \mathrm{D}, 100 \mathrm{D} /(\mathrm{D}+\mathrm{L})$ where $\mathrm{D}=$ amount of $\mathrm{D}$-amino acid, $\mathrm{L}=$ amount of L-amino acid.

${ }^{3} \mathrm{RSD}=$ Relative standard deviation $(\mathrm{n}=4)$. 

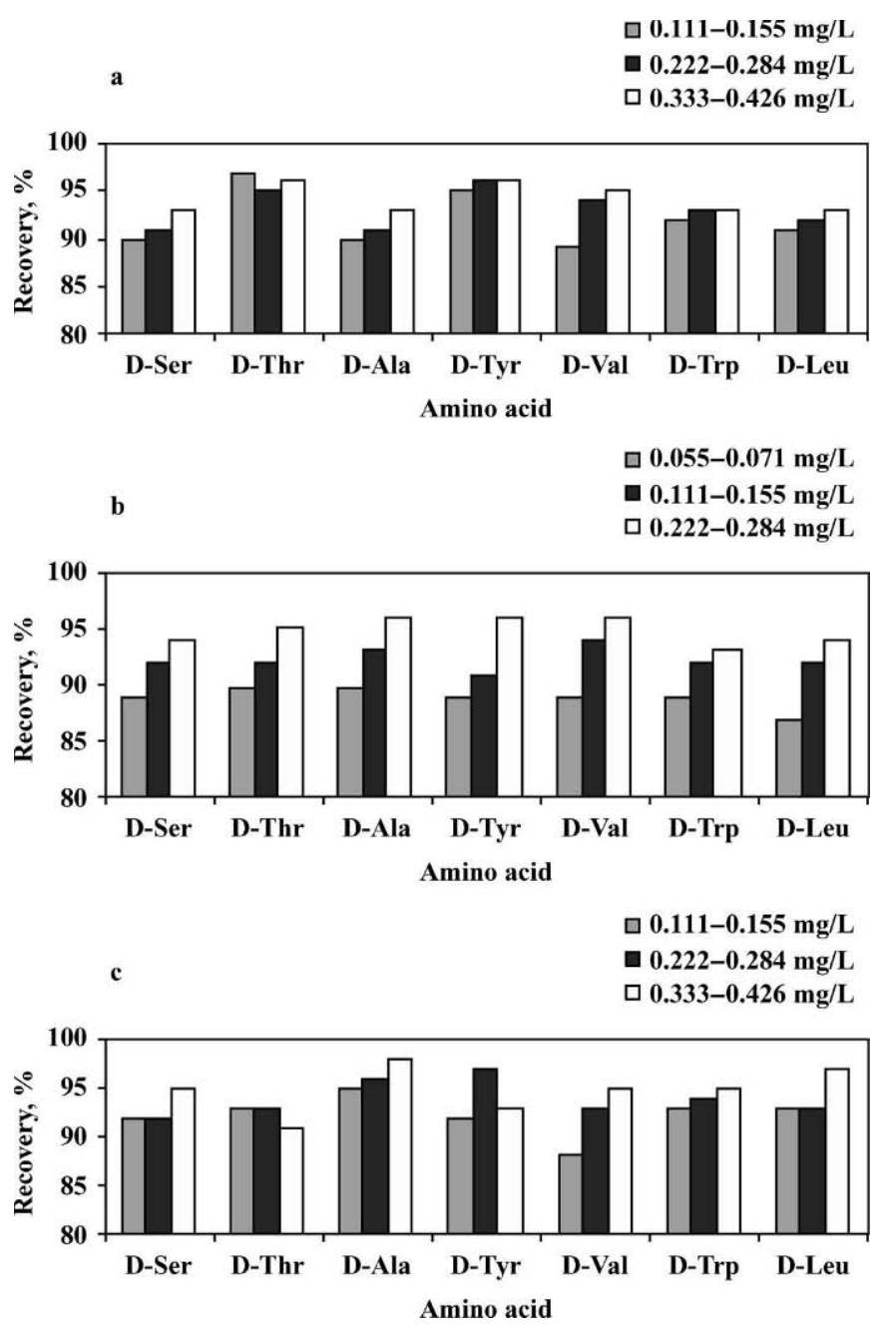

Figure 2. Recovery studies of D-amino acids in milk samples; a) whole milk; b) half-cream; and c) skimmed milk.

than $9 \%(\mathrm{n}=4)$. Similar recovery results and RSD values for the nonenzymatic procedure were obtained. Under our experimental conditions, amino acid racemization was not observed.

\section{CONCLUSIONS}

The proposed analytical methodology simplifies both sample treatment and chromatographic separation of D-amino acids. Results showed the presence of D-Ser, D-Ala, D-Tyr, D-Trp, and D-Leu in milk, and D-Thr, DAla, and D-Val in oyster samples. Only D-Ala was present in both types of samples. The relative amounts of D-Trp and D-Leu are high in milk samples. The content of D-AA is higher in oyster samples than in milk samples. These data may be useful in studies about the beneficial or harmful effects of D-AA.
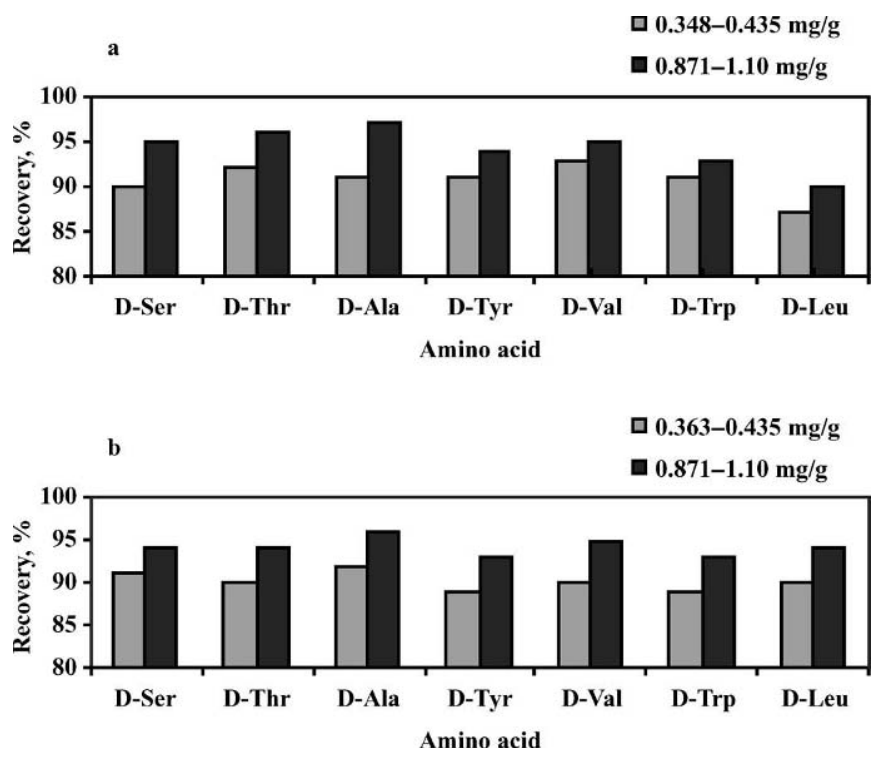

Figure 3. Recovery studies of D-amino acids in oyster samples obtained by the enzymatic method; a) lyophilized oyster samples, and b) fresh oyster samples.

\section{ACKNOWLEDGMENTS}

The financial support of the Spanish DGICYT project PQU2003-00667 is gratefully acknowledged; A. Gutierrez-Carreras supplied oyster samples and this is gratefully acknowledged.

\section{REFERENCES}

Biasiolo, M., A. Bertazzo, C. Costa, A. Beghetto, and G. Allegri. 1995. Determination of nonprotein tryptophan in yoghurts by selective fluorescence and HPLC. Food Chem. 52:87-92.

Boehm, G., H. Cervantes, G. Georgi, J. Jelinek, G. Sawatzki, B. Wermuth, and J. P. Colombo. 1998. Effect of increasing dietary threonine intakes on amino acid metabolism of the central nervous system and peripheral tissues in growing rats. Pediatr. Res. 44:900-906.

Brückner, H., and M. Hausch. 1990. D-Amino acids in dairy products: Detection, origin and nutritional aspects. II. Ripened cheeses. Milchwissenschaft 45:421-425.

Brückner, H., M. Langer, M. Lupke, T. Westhanser, and H. Godel. 1995. Liquid chromatographic determination of amino acid enantiomers by derivatization with o-phthaldialdehyde and chiral thiols. Applications with reference to food sciences. J. Chromatogr. A 697:229-245.

Brückner, H., and A. Schieber. 2001. Determination of amino-acid enantiomers in human urine and blood serum by gas chromatography-mass spectrometry. Biomed. Chromatogr. 15:166-172.

Buck, R. H., and K. Krummen. 1987. High-performance liquid chromatographic determination of enantiomeric amino acids and amino alcohols after derivatization with o-phthaldialdehyde and various chiral mercaptans. Applications to peptide hydrolysates. J. Chromatogr. 387:255-265.

Casal, S., M. B. Oliveira, and M. A. Ferreira. 2000. Gas chromatographic quantification of amino acid enantiomers in food matrices by their $\mathrm{N}(\mathrm{O}, \mathrm{S})$-ethoxycarbonyl heptafluorobutyl ester derivatives. J. Chromatogr. A 866:221-230. 
Cesapó, J., Z. Cesapó-Kiss, J. Stefler, T. G. Martín, and S. Némethy. 1995. Influence of mastitis on D-amino acid content of milk. J. Dairy Sci. 78:2375-2381.

Chang, H. M., C. F. Tsai, and C. F. Li. 1998. Enantiomeric separation of Dns-DL-amino acids by gamma-cyclodextrin-modified micellar capillary electrophoresis. J. Agric. Food Chem. 46:4598-4603.

Erbe, T., and H. Brückner. 2000. Chromatographic determination of amino acid enantiomers in beers and raw materials used for their manufacture. J. Chromatogr. A 881:81-91.

Estevens, E. R., M. Esguerra, P. M. Kim, E. A. Newman, S. H. Snyder, K. R. Zahs, and R. F. Miller. 2003. D-Serine and serine-racemase are present in the vertebrate retina and contribute to the physiological activation of NMDA receptors. Proc. Nat. Acad. Sci. USA 100:6789-6794.

Felbeck, H., and S. Wiley. 1987. Free D-amino acids in the tissues of marine bivalves. Biol. Bull. 173:252-259.

Fisher, G. H. 1998. Appearance of D-amino acids during aging: Damino acids in tumor proteins. EXS 85:109-118.

Ganote, C. E., D. R. Peterson, and F. A. Carone. 1974. The nature of D-serine-induced nephrotoxicity. Am. J. Pathol. 77:269-276.

Gonzalez-Hernández, J. C., L. Aguilera-Aguirre, V. Pérez-Vazquez, J. Ramírez, M. Clemente-Guerrero, C. Cortés-Rojo, and A. Saavedra-Molina. 2003. Effect of the amino acids on some mitochondrial functions in rat liver. Amino Acids 24:163-169.

Hamase, K., A. Morikawa, and K. Zaitsu. 2002. D-amino acids in mammals and their diagnostic value. J. Chromatogr. B 781:73-91.

Hansford, K. A., R. C. Reid, C. I. Clark, J. D. A. Tyndall, M. W. Whitehouse, T. Guthrie, R. P. McGeary, K. Schafer, J. L. Martin, and D. P. Fairlie. 2003. D-Tyrosine as a chiral precursor to potent inhibitors of human nonpancreatic secretory phospholipase A2 (IIa) with anti-inflammatory activity. Chembiochem 4:181-185.

Jin, D., T. Miyahara, T. Oe, and T. Toyo'oka. 1999. Determination of D-amino acids labeled with fluorescent chiral reagents, $\mathrm{R}(-)$ and S(+)-4-(-3-Isothiocyanatopyrrolidin-1-yl)-7-(N,N-dimethylaminosulfonyl)-2,1,3-benzoxadiazoles, in biological and food samples by liquid chromatography. Anal. Biochem. 269:124-132.
Kato, M., T. Fukushima, T. Santa, K. Nakashima, R. Nishioka, and K. Imai. 1998. Preparation and evaluation of new Pirkle-type chiral stationary phases with long alkyl chains for the separation of amino-acid enantiomers derivatized with NBD-F. Analyst 123:2877-2882.

Lee, J., K. R. Kim, S. Won, H. J. Kim, and J. Goto. 2001. Enantioseparation of chiral amino acids as the $\mathrm{N}(\mathrm{O}, \mathrm{S})$-ethoxycarbonylated diastereomeric esters by achiral dual-capillary column gas chromatography. Analyst 126:2128-2133.

Man, E. H., and J. L. Bada. 1987. Dietary D-amino acids. Annu. Rev. Nutr. 7:209-225.

Miller, R. F. 2004. D-Serine as a glial modulator of nerve cells. Glia 47:275-283.

Petritis, K., A. Valleix, C. Elfakir, and M. Dreux. 2001. Simultaneous analysis of underivatized chiral amino acids by liquid chromatography-ionspray tandem mass spectrometry using a teicoplanin chiral stationary phase. J. Chromatogr. A 913:331-340.

Quijano, M. A., P. Moreno, A. M. Gutierrez, M. C. Pérez-Conde, and C. Cámara. 2000. Selenium speciation in animal tissues after enzymatic digestion by high-performance liquid chromatography coupled to inductively plasma mass spectrometry. J. Mass Spectrom. 35:878-884.

Stegman, L. D., H. Zheng, E. R. Neal, O. Ben-Yoseph, L. Pollegioni, M. S. Pilone, and B. D. Ross. 1998. Induction of cytotoxic oxidative stress by D-alanine in brain tumor cells expressing Rhodotorula gracilis D-amino acid oxidase: A cancer gene therapy strategy. Hum. Gene Ther. 9:185-193.

Vandenabeele-Trambouze, O., M. Albert, C. Boyle, F. Couderc, A. Commeyras, D. Despois, M. Dobrijevic, and M. F. Grenier-Loustalot. 2000. Chiral determination of amino acids by capillary electrophoresis and laser-induced fluorescence at picomolar concentrations. J. Chromatogr. A 894:259-266.

Williams, A. P. 1988. Determination of Amino Acids. Page 441 in HPLC in Food Analysis. R. Macrae, ed. Academic Press, New York, NY.

Wolosker, H., R. Panizzutti, and J. De Miranda. 2002. Neurobiology through the looking-glass: D-serine a new glial-derived transmitter. Neurochem. Int. 41:327-332. 